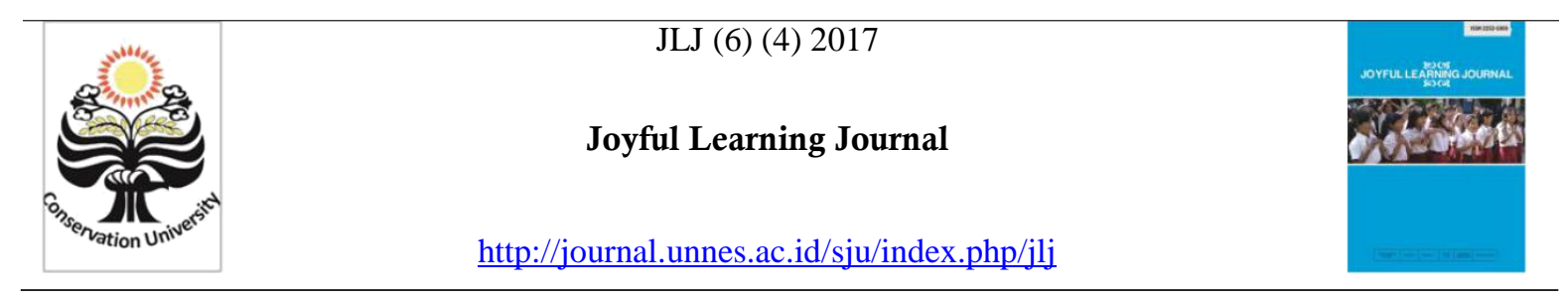

\title{
PERMAINAN MONOPOLI SEBAGAI MEDIA PEMBELAJARAN MATEMATIKA
}

\section{Budi Adi Prayogo $\square$, Trimurtini, Sukarjo.}

Jurusan Pendidikan Guru Sekolah Dasar, Fakultas Ilmu Pendidikan, Universitas Negeri Semarang,Indonesia

Info Artikel

Sejarah Artikel: Diterima Oktober 2017

Disetujui

November

2017

Dipublikasikan

Desember 2017

Keywords: learning media, monopoly game, mathematic learning result.

\begin{abstract}
Abstrak
Tujuan penelitian ini untuk mengetahui pengembangan, kelayakan dan keefektifan media permainan monopoli mata pelajaran matematika sebagai media yang layak dan untuk meningkatkan hasil belajar kognitif kelas II SD. Jenis penelitian ini adalah penelitian pengembangan menggunakan metode Research and Development . Populasi penelitian ini adalah peserta didik kelas II SDN Langensari 02. Teknik pengumpulan data menggunakan angket, wawancara, dokumentasi, observasi, dan tes. Analisis data menggunakan uji validitas, Reliabilitas, Normalitas, Homogenitas, N-gain, dan t-Test. Hasil Penelitian menunjukan bahwa, penilaian pakar ahli materi sebesar 92,64\% (sangat layak) dan ahli media sebesar 91,66\% (sangat layak). Media yang dikembangkan mampu meningkatkan ketuntasan klasikal 26,08\% menjadi 100\%. Jadi, dapat disimpulkan bahwa Media Permainan Monopoli Mata Pelajaran Matematika Materi Penjumlahan dan Pengurangan bilangan 1 sampai 500 di Kelas II SD layak digunakan.
\end{abstract}

\begin{abstract}
The purpose of this study was to know development, properness, and effectiveness of monopoly game media in Mathematics as a proper media and to improve cognitive learning outcomes of second grade of elementary school. The type of this study was research development which used Research and Development method. The population of this study was the second grade students of SDN Langensari 02. The Technique of the data collection used questionnaire, interview, documentation, observation, and test. The data analysis used validity, reliability, normality, homogeneity, $\mathrm{N}$-gain, and t-test. The results of the study showed that, the expert material's assessment as many as $92,64 \%$ (very proper) and from media expert as many as $91,66 \%$ (very proper).The media which is being developed is able to increase classical mastery from $26.08 \%$ to $100 \%$. Thus, it can be concluded that Monopoly Game Media in Mathematics especially in Addition and Substraction material of number 1 up to 500 in the second grade of elementary school was proper to be used.
\end{abstract}




\section{PENDAHULUAN}

Berdasarkan UU Nomor 20 Tahun 2003

Pasal 1 ayat 1 tentang Sistem Pendidikan Nasional menyatakan bahwa pendidikan adalah usaha sadar dan terencana untuk mewujudkan suasana belajar dan proses pembelajaran agar peserta didik secara aktif mengembangkan potensi dirinya. Kurikulum pendidikan di Indonesia memuat beberapa pelajaran pokok yaitu Matematika, Bahasa Indonesia, IPA, IPS, PKn, Pendidikan Agama, dan Pendidikan Jasmani. Mata pelajaran matematika adalah salah satu mata pelajaran yang wajib diajarkan kepada siswa sejak jenjang Sekolah Dasar (SD)/ Madrasah Ibtidaiyah (MI), pernyataan ini terdapat pada Peraturan Menteri Pendidikan Nasional (Permendiknas) No. 22 Th. 2006 tentang Standar Isi. Permendiknas No. 22 Th. 2006 sebagai acuan pelaksanaan pembelajaran di Indonesia menjelaskan bahwa pembelajaran matematika di sekolah dasar salah satunya bertujuan untuk memahami konsep matematika dan mengaplikasikannya dalam pemecahan masalah secara tepat.

Dalam proses pembelajaran matematika, baik guru maupun siswa bersama-sama menjadi pelaku terlaksananya tujuan pembelajaran. Tujuan pembelajaran ini akan mencapai hasil yang maksimal apabila pembelajaran berjalan secara efektif. Pembelajaran matematika yang efektif adalah pembelajaran yang mampu melibatkan seluruh siswa secara aktif. Kualitas pembelajaran dapat dilihat dari segi hasil. Marpaung (dalam Royani, 2008: 103) mengungkapkan tentang kesalahan dalam pembelajaran matematika yang umumnya dilakukan, yaitu: guru memberi tahu konsep, sifat, teorema, dan cara menggunakan kepada siswa.. Berbagai permasalahan yang diungkapkan tersebut menunjukkan bahwa kualitas pembelajaran matematika di Indonesia masih belum optimal.
Pada

kenyataanya,permasalahan

pembelajaran Matematika tersebut juga masih terjadi di sekolah dasar. Berdasarkan hasil observasi dan wawancara pada tanggal 5-7 Januari 2017 di SDN Langensari 02 Kecamatan Ungaran Barat, berdasarkan data nilai UAS siswa kelas II semester I tahun 2016/201, dari 5 mata pelajaran yang diujikan pada Ujian Nasional (UN) Sekolah Dasar (SD) yaitu PPKn, Matematika, Bahasa Indonesia, IPA dan IPS, rata-rata nilai pelajaran matematika di kelas II merupakan yang terendah, Hal ini ditunjukkan dengan data, dari 23 siswa hanya 8 siswa (35\%) yang nilainya melampaui KKM sedangkan 15 siswa lainnya (65\%) mendapatkan nilai dibawah KKM yang sudah ditentukan yaitu 65 .

. Dengan adanya permasalahan seperti yang telah dijelaskan, penelitian ini akan mengkaji mengenai penggunaan media pembelajaran monopoli untuk meningkatkan minat dan hasil belajar siswa terhadap matematika

Penelitian ini juga didasarkan pada hasil penelitian sebelumnya yang mengembangkan media permainan monopoli. Beberapa penelitian yang dapat dijadikan sebagai acuan dalam penelitian yang akan peneliti lakukan adalah pertama, penelitian yang dilakukan penelitian yang dilakukan oleh Nur Azizah ( JPGSD Vol 01 : 2012) dengan judul Penerapan Media Monopoli Untuk Meningkatkan Hasil Belajar Siswa Pada Mata Pelajaran IPA Di Sekolah Dasar. Hasil penelitian menunjukkan bahwa hasil observasi aktivitas guru mengalami peningkatan sebesar $9 \%$ dari $83 \%$ pada siklus I menjadi $92 \%$ pada siklus II. Hasil observasi aktivitas siswa mengalami peningkatan sebesar $11 \%$ dari $79 \%$ pada siklus I menjadi $90 \%$ pada siklus II. Hasil belajar siswa mengalami peningkatan $22 \%$ dari $73 \%$ pada siklus I menjadi 90\% pada siklus II.. Kedua, oleh Solekhah Volume 09 No. 07 Tahun 2015 dengan judul Pengembangan Media Monopoli Tematik Pada Tema "Tempat Tinggalku" Untuk Siswa Kelas IV SD N Babarsari. Hasil penelitian 
menunjukkan bahwa penilaian dari ahli media mendapatkan rata-rata skor 3,9 termasuk kategorilayak. Penilaian ahli materi mendapatkan rata-rata skor 4,8 termasuk kategori layak. Uji coba lapangan operasional mendapatkan persentase skor 97,5\% termasuk dalam kategori layak. Dapat disimpulkan bahwa media Monopoli Tematik untuk pembelajaran tematik siswa kelas IV Sekolah Dasar layak digunakan. Ketiga Penelitian Zuhri Firdaus Vol. 07 No. 02 Tahun 2014 mengadakan penelitian tentang pengembangan permainan monopoli IPA materi Sistem Pencernaan. Nilai persentase penilaian media monopoli IPA materi sistem pencernaan makanan oleh ahli media, ahli materi, praktisi lapangan dan siswa berturut-turut adalah $86 ; 85,6 ; 85 ; 85$ dengan tingkat validitas sangat tinggi. Kesimpulan secara keseluruhan, media permainan monopoli IPA layak digunakan untuk membantu siswa

belajar materi sistem pencernaan makanan. Keempat, penelitian yang dilakukan Dias Hendyanto Dwiputra Vol. 08 No. 06 Tahun 2016 melakukan Penelitian pengembangan yang bertujuan untuk menghasilkan media monopoli penggolongan hewan yang layak digunakan untuk pembalajaran IPA kelas 4 Sekolah Dasar. Kelima, Danelia Elivas Hestunar Vol. 08 No. 05 Tahun 2014 melakukan penelitian di SMP Terang Bangsa, Berdasarkan hasil pengamatan checklist, kuesioner, dan validasi ahli itu menunjukkan bahwa Permainan Gladden Monopoli membantu dalam belajar bahasa Inggris. Hal ini dapat dilihat dari hasil jawaban dari kuesioner di mana lebih dari 75\% dari siswa menjawab 'A' atau 'B' yang menunjukkan bahwa produk tersebut mudah dan menarik untuk digunakan.. Keenam, penelitian yang dilakukan oleh Vivi Agustin Vol. 03 No. 09 Tahun 2013 penelitian yang dia lakukan merupakan jenis penelitian pengembangan, yaitu dengan mengembangkan media pembelajaran MoGe (Monopoli Geografi) melalui model ASSURE sekaligus menilai kelayakan MoGe (Monopoli
Geografi) sebagai media pembelajaran pada pokok bahasan menganalisis hubungan antara manusia dengan lingkungan sebagai akibat dari dinamika atmosfer.. Ketujuh, penelitian yang dilakukan Purwanto Vol. 17 No.01 Tahun 2012 melakukan penelitian yang bertujuan untuk mengetahui peningkatan prestasi belajar dan profil kemampuan berpikir kritis siswa setelah diimplementasikannya permainan Monopoli Fisika dalam pembelajaran kooperatif tipe TeamGames Tournament. Hasil penelitian yang diperoleh menunjukkan bahwa siswa di sekolah tersebut mengalami peningkatan dalam prestasi belajarnya setelah diimplementasikannya permainan monopoli Fisika dalam pembelajaran

Dari ulasan latar belakang tersebut maka peneliti akan mengkaji melalui penelitian pengembangan R\&D dengan judul "Pengembangan Permainan Monopoli Sebagai Media Pembelajaran Matematika Pada Siswa Kelas II SDN Langensari 02 Kecamatan Ungaran Barat".

\section{METODE PENELITIAN}

Desain penelitian yang digunakan adalah model pengembangan menurut Sugiyono. Model ini dipilih karena sesuai dengan penelitian pengembangan yang akan dilakukan oleh peneliti. Subjek dalam penelitian ini adalah siswa kelas kelas II A SDN Langensari 02 sebanyak 23 siswa, dan siswa kelas II A SDN Langensari 02 sebanyak 21 siswa. Sedangkan untuk uji coba soal dilakukan di kelas II SD N Langensari 03 sebanyak 21 siswa. Siswa dijadikan subjek saat peneliti menganalisis kebutuhan media permainan monopoli, uji coba soal, uji coba produk (skala kecil), dan uji coba pemakaian (skala besar). Guru kelas II SD Langensari 02 , dijadikan subjek saat peneliti menganalisis kebutuhan media permainan monopoli, mengajar untuk 
kelas kontrol, uji coba produk (skala kecil), dan uji coba pemakaian (skala besar).

Teknik pengumpulan data yang peneliti gunakan yaitu wawancara, observasi, angket, tes dan dokumentasi. Sebelum instrumen tes digunakan, sebelumnya dilakukan uji validitas dan uji reliabilitas terlebih dahulu agar instrumen valid dan reliabel untuk pengambilan data.

Analisis data menggunakan uji validitas,Reliabilitas,Normalitas,Homogentias, Uji Z Uji gain dan $\mathrm{N}$-gain, serta Uji t. Uji normalitas digunakan untuk melihat apakah data yang akan diuji berdistribusi normal atau tidak, $\mathrm{N}$-gain untuk melihat peningkatan ratarata hasil belajar, uji t-Test untuk mengetahui keefektifan media. Dalam menghitung data penelitian, peniliti menggunakan Microsoft Office Excel 2007.

\section{HASIL DAN PEMBAHASAN}

Penilaian kelayakan media permainan moopoli dilakukan oleh pakar materi, dan pakar media. Penilaian kelayakan media permainan monopoli dilakukan dengan menilai masingmasing aspek meliputi aspek materi dan media.

Selain hasil validasi dari para pakar, penggunaan media permainan monopoli materi penjumlahan dan pengurangan bilangan 1 sampai 500 juga mendapatkan tanggapan dari siswa dan guru. Tanggapan tersebut diperoleh melalui angket respon siswa dan guru.

\section{Uji Normalitas Pretest}

Sebelum dilakukan penelitian pada kelas II SD N Langensari 02, terlebih dahulu diberikan pretest yang digunakan untuk mengetahui sejauh mana tingkat pemahaman peserta didik terhadap materi. Hasil pretest kemudian diuji normalitas dengan menggunakan Lilliefors. Hasil perhitungan uji normalitas pada nilai pretest dengan rata-rata 63,85 dan standar deviasi sebesar 11,27. Diketahui harga $\mathrm{L}_{\text {hitung }}<\mathrm{L}_{\text {tabel. }}$. Diperoleh $\mathrm{L}_{\text {hitung }} 0,161$ dengan $\mathrm{dk}=20$. Dan $\alpha=$ $5 \%$, diperoleh $\mathrm{L}_{\text {tabel }}=0,190$. Hal tersebut menunjukkan nilai pretest berdistribusi normal.

\section{Uji Normalitas Postest.}

Hasil postest kemudian diuji normalitas dengan menggunakan uji Lillifors. Hasil perhitungan uji normalitas pada nilai postest dengan rata-rata 89,19 dan standar deviasi sebesar 7,96. Diketahui harga $\mathrm{L}_{\text {hitung }}<\mathrm{L}_{\text {tabel. }}$. Diperoleh $\mathrm{L}_{\text {hitung }}=0,132$ dengan $\mathrm{dk}=20$. Dan $\alpha=5 \%$, diperoleh $\mathrm{L}_{\text {tabel }}=0,190$. Hal ini menunjukkan nilai postest berdistribusi normal.

\section{Hasil Analisis Uji Homogenitas (Post test)}

Perhitungan uji homogenitas dilakukan dengan meggunakan uji F Hasil uji homogenitas menunjukkan bahwa $F_{\text {hitung }}=0,129$ sedangkan $\mathrm{F}_{\text {tabel }}$ pada $\alpha=0,05$ dengan $\mathrm{dk}$ pembilang $=23-1$ $=22$ dan $\mathrm{dk}$ penyebut $=21-1=20 \quad$ adalah 2,18 . Sehingga dapat ditarik kesimpulan bahwa $\mathrm{F}_{\text {hitung }}<\mathrm{F}_{\text {tabel }}$ sehingga varians kedua sampel tersebut homogen

\section{Hasil Uji Ketuntasan Belajar dengan Media Permainan monopoli}

Uji ketuntasan belajar bertujuan untuk mengetahui hasil belajar menggunakan permainan monopoli dapat mencapai ketuntasan belajar atau tidak. Pada penelitian ini, pembelajaran mencapai ketuntasan belajar klasikal jika persentase peserta didik sekurangkurangnya $75 \%$ dari jumlah peserta didik yang ada di kelas tersebut, telah tuntas belajar. Diperoleh $Z_{\text {hitung }} \geq Z_{\text {tabel }}$ sehingga dapat disimpulkan bahwa pembelajaran dengan menggunakan media permainan monopoli dikatakan tuntas secara klasikal karena persentase peserta didik yang memperoleh nilai tes akhir lebih dari 75 telah mencapai $75 \%$ atau lebih. 


\section{Hasil Uji Keefektifan Media}

Uji perbedaan dua rata-rata dilakukan untuk mengetahui keefektifan media permainan monopoli terhadap hasil belajar matematika materi penjumlahan dan pengurangan bilangan 1 sampai 500 kelas II SD N Langensari 02. Pada penelitian ini data yang digunakan untuk menguji keefektifan pembelajaran yaitu data hasil tes siswa baik kelas eksperimen dan kontrol. Uji perbedaan dua rata-rata dilakukan dengan menggunakan uji rata-rata satu pihak (uji t), diperoleh $t_{\text {hitung }}=24,85$ sedangkan $t_{\text {tabel }}=1,68$ dengan taraf signifikan $5 \%$ dan $\mathrm{n}_{1}+\mathrm{n}_{2}-2=21+$ 23-2 $=42$. Berdasarkan hasil analisis tersebut diperoleh $t_{\text {hitung }} \geq t_{\text {tabel }}$ maka dapat disimpulkan bahwa hasil belajar kelas eksperimen lebih baik daripada kelas kontrol. Dengan kata lain, media permainan monopoli lebih efektif daripada media kelas kontrol yaitu gambar, terhadap hasil belajar matematika materi penjumlahan dan pengurangan bilangan 1 sampai 500 kelas II SD $\mathrm{N}$ Langensari 02

\section{Hasil Uji gain dan N-gain}

Guna mendukung hasil uji kefektifan media, maka peneliti menggunakan analisis data gain dan N-Gain yang merupakan data peningkatan kemampuan siswa antar nilai pretest dan posttest kelas eksperimen dan kelas kontrol.

Data gain digunakan untuk mengetahui peningkatan kemampuan siswa antara sebelum dan sesudah pemberian perlakuan. Data N-Gain atau gain ternormalisasi untuk melihat peningkatan hasil belajar siswa, dan nilai $\mathrm{N}$ Gain tersebut akan dilihat efektifitas penggunaan media permainan monopoli dalam pembelajaran matematika materi penjumlahan dan pengurangan bilangan 1 sampai 500 . Ratarata tes awal kelas eksperimen sebesar 63,85 dan rata-rata tes akhir sebesar 89,19. Berdasarkan perbedaan rata-rata yang diperoleh tersebut hasil belajar matematika materi penjumlahan dan pengurangan bilangan 1 samapai 500 sebelum dan sesudah memperoleh pembelajaran dengan media permainan monopoli mengalami peningkatan sebesar 25,33 dengan kategori peningkatan sedang. Selain itu, berdasarkan hasil analisis indeks gain ternormalisasi diperoleh hasil sebesar 0,731. Artinya hasil belajar siswa pada kelas eksperimen mengalami peningkatan taraf tinggi

\section{SIMPULAN}

Berdasarkan hasil penelitian menyebutkan bahwa pengembangan media permainan monopoli pada pembelajaran matematika materi penjumlahan dan pengurangan bilangan 1 sampai 500 efektif untuk pembelajaran kelas II

\section{UCAPAN TERIMAKASIH}

Terimakasih kepada Allah SWT orang tua yang telah memberikan doa dan semangat. Pembimbing utama Trimurtini, S.Pd, M.Pd. dan Drs. Sukarjo, S.Pd, M.Pd, yang telah memberikan bimbingan pada penelitian ini

\section{DAFTAR PUSTAKA}

Agustin Vivi. 2013. media pembelajaran MoGe (Monopoli Geografi) melalui model ASSURE. Indonesian Jurnal On Computer Science. Volume 10 No 2

Azizah Nur.2012. Media monopoli untuk meningkatkan hasil belajar siswa SDN Sidoarjo. Jurnal Nasional Vol.2 No.34

Danelia Elivas Hestunar. 2014. Permainan Gladden monopoli materi kosa kata siswa kelas tujuh. Jurnal Nasional. Volume 32 No 3

Daryanto.2016. Media Pembelajaran. Yogjakarta : Gava Media

Purwanto.2014. Permainan Monopoli Fisika dalam pembelajaran kooperatif tipe Team Games Tournament. Jurnal Nasional. Volume 2 No 4 
Hendyanto Dyas Dwiputra. 2016. Pengembangan Media media monopoli penggolongan hewan kelas IV Sekolah Dasar. Unnes Journal. Volume 2 No 2

Lestari, Eka Karunia dan Mokhammad Ridwan Yudhanegara. 2015. Penelitian Pendidikan Matematika. Bandung: Refika Aditama.

Permendikbud nomor 22 Tahun 2016 tentang Standar Proses Pendidikan Dasar dan Menengah

Permendiknas Nomor 22 Tahun 2006 tentang Standar Isi Untuk Satuan Pendidikan Dasar dan Menengah
Sudjana. 1975. Metoda Statistika.Bandung: Tarsito

$\begin{array}{crr}\text { Sugiyono.2015. } & \text { Metode } & \text { Penelitian } \\ \text { Pendidikan. } & \text { Bandung:Alfabeta }\end{array}$

Slameto.2013.Belajar dan Faktor-Faktor yang Mempengaruhi. Jakarta: PT Asdi Mahasatya

Susanto Ahmad. 2016. Teori Belajar Dan Pembelajaran.jakarta: Prenadamedia Group

Undang-Undang Sisdiknas Nomor 20 Tahun 2003 pasal 1 Tentang Pendidikan

Zuhri Firdaus. 2014. Pengembangan Permainan monopoli IPA di SMP $N$ Malang. Jurnal Pendidikan IPA. Volume 04 No 03 
